ANNALES

POLONICI MATHEMATICI

$86.2(2005)$

\title{
Periodic solutions for some delay differential equations appearing in models of power systems
}

\author{
by Bingwen Liu (Changde) and Lihong Huang (Changsha)
}

\begin{abstract}
The authors use coincidence degree theory to establish some new results on the existence of $T$-periodic solutions for the delay differential equation

$$
x^{\prime \prime}(t)+a_{1} x^{\prime}(t)+a_{2}\left(x^{n}(t)\right)^{\prime}+a_{3} x(t)+a_{4} x(t-\tau)+a_{5} x^{n}(t)+a_{6} x^{n}(t-\tau)=f(t),
$$

which appears in a model of a power system. These results are of practical significance.
\end{abstract}

1. Introduction. An excess voltage of ferro-resonance known as some kind of nonlinear resonance enjoying long duration arises from magnetic saturation of inductance in an oscillating circuit of a power system, and a boosted excess voltage can give rise to some problems in relay protection. To probe into its mechanism, the following mathematical model was proposed in $[8,9]$ :

$$
\begin{aligned}
x^{\prime \prime}(t)+a_{1} x^{\prime}(t)+a_{2}\left(x^{n}(t)\right)^{\prime}+a_{3} x(t) & +a_{4} x(t-\tau) \\
& +a_{5} x^{n}(t)+a_{6} x^{n}(t-\tau)=f(t),
\end{aligned}
$$

where $a_{1}, \ldots, a_{6}$ are nonnegative constants, the delay $\tau>0$ is a constant, $n \geq 3$ is an odd integer, and $f: \mathbb{R} \rightarrow \mathbb{R}$ is a continuous periodic function with period $T>0$. Since a normally functioning power system is considered to be a periodic or almost periodic motion (see $[2,9]$ ), it is worth while to study the existence of periodic solutions of equation (1.1).

In this paper, using the continuation theorem of coincidence degree theory, we will give some results on the existence of a $T$-periodic solution to equation (1.1), which are of practical significance.

2000 Mathematics Subject Classification: 34C25, 34D40, 34K15.

Key words and phrases: delay differential equation, periodic solution, existence, coincidence degree.

This work was supported by the NNSF (10371034) of China, the Doctor Program Foundation of the Ministry of Education of China (20010532002) and the Key Project of the Chinese Ministry of Education ([2002]78). 
For ease of exposition, throughout this paper we will adopt the following notations:

$$
|x|_{k}=\left(\int_{0}^{T}|x(t)|^{k} d t\right)^{1 / k}, \quad|x|_{\infty}=\max _{t \in[0, T]}|x(t)|, \quad F(t)=\int_{0}^{t} f(s) d s .
$$

Let

$$
X=\left\{x \in C^{1}(\mathbb{R}, \mathbb{R}) \mid x(t+T)=x(t) \text { for all } t \in \mathbb{R}\right\},
$$

and

$$
Y=\{x \in C(\mathbb{R}, \mathbb{R}) \mid x(t+T)=x(t) \text { for all } t \in \mathbb{R}\}
$$

be two Banach spaces with the norms

$$
\|x\|_{X}=\max \left\{|x|_{\infty},\left|x^{\prime}\right|_{\infty}\right\} \text { and }\|x\|_{Y}=|x|_{\infty} .
$$

Define a linear operator $L: D(L) \subset X \rightarrow Y$ by setting

$$
D(L)=\left\{x \in X \mid x^{\prime \prime} \in C(\mathbb{R}, \mathbb{R})\right\}
$$

and for $x \in D(L)$,

$$
L x=x^{\prime \prime} .
$$

We also define a nonlinear operator $N: X \rightarrow Y$ by setting

$$
\begin{aligned}
N x= & -a_{1} x^{\prime}(t)-a_{2}\left(x^{n}(t)\right)^{\prime}-a_{3} x(t)-a_{4} x(t-\tau) \\
& -a_{5} x^{n}(t)-a_{6} x^{n}(t-\tau)+f(t) .
\end{aligned}
$$

It is easy to see that

$$
\operatorname{Ker} L=\mathbb{R}, \quad \operatorname{Im} L=\left\{x \in Y \mid \int_{0}^{T} x(s) d s=0\right\} .
$$

Thus, $L$ is a Fredholm operator with index zero.

Define continuous projectors $P: X \rightarrow \operatorname{Ker} L$ and $Q: Y \rightarrow Y / \operatorname{Im} L$ by setting

$$
P x(t)=x(0)=x(T), \quad Q x(t)=\frac{1}{T} \int_{0}^{T} x(s) d s .
$$

Hence, $\operatorname{Im} P=\operatorname{Ker} L$ and $\operatorname{Ker} Q=\operatorname{Im} L$. Denoting by $L_{P}^{-1}: \operatorname{Im} L \rightarrow D(L) \cap$ Ker $P$ the inverse of $\left.L\right|_{D(L) \cap K e r} P$, we have

$$
L_{P}^{-1} y(t)=-\frac{t}{T} \int_{0}^{T}(t-s) y(s) d s+\int_{0}^{t}(t-s) y(s) d s .
$$

2. Preliminary results. In view of (1.2) and (1.3), the operator equation

$$
L x=\lambda N x
$$


is equivalent to the equation

$$
\begin{aligned}
x^{\prime \prime}+\lambda\left[a_{1} x^{\prime}(t)+\right. & a_{2}\left(x^{n}(t)\right)^{\prime}+a_{3} x(t) \\
& \left.+a_{4} x(t-\tau)+a_{5} x^{n}(t)+a_{6} x^{n}(t-\tau)\right]=\lambda f(t),
\end{aligned}
$$

where $\lambda \in(0,1)$.

For convenience, we introduce the Continuation Theorem [3] as follows.

Lemma 2.1. Let $X$ and $Y$ be two Banach spaces. Suppose that $L$ : $D(L) \subset X \rightarrow Y$ is a Fredholm operator of index zero, and $N: \bar{\Omega} \rightarrow Y$ is L-compact on $\bar{\Omega}$, where $\Omega$ is an open bounded subset of $X$. Moreover, assume that the following conditions are satisfied:

(1) $L x \neq \lambda N x, \forall x \in \partial \Omega \cap D(L), \lambda \in(0,1)$;

(2) $N x \notin \operatorname{Im} L, \forall x \in \partial \Omega \cap \operatorname{Ker} L$;

(3) The Brouwer degree

$$
\operatorname{deg}\left\{\left.Q N\right|_{N(L)}, \Omega \cap \operatorname{Ker} L, 0\right\} \neq 0 .
$$

Then the equation $L x=N x$ has a solution in $\bar{\Omega} \cap D(L)$.

The following lemmas will be useful to prove our main results in Section 3 .

LEMMA 2.2. If $x \in C^{2}(\mathbb{R}, \mathbb{R})$ with $x(t+T)=x(t)$, then

$$
\left|x^{\prime}(t)\right|_{2}^{2} \leq\left(\frac{T}{2 \pi}\right)^{2}\left|x^{\prime \prime}(t)\right|_{2}^{2}
$$

Proof. This is known as the Wirtinger inequality; see $[14,15]$ for the proof.

Lemma 2.3. Let $x(t)$ be a T-periodic solution of $(2.1)_{\lambda}$. Suppose that there exists a constant $D>0$ such that

$$
\left|x\left(\tau_{0}\right)\right|<D, \quad \tau_{0} \in[0, T] .
$$

Then

$$
|x|_{2} \leq \frac{T}{\pi}\left|x^{\prime}\right|_{2}+\sqrt{T} D
$$

Proof. Let

Then

$$
y(t)= \begin{cases}x\left(t+\tau_{0}-T\right)-x\left(\tau_{0}\right), & T-\tau_{0} \leq t \leq T \\ x\left(t+\tau_{0}\right)-x\left(\tau_{0}\right), & 0 \leq t<T-\tau_{0}\end{cases}
$$

$$
y(0)=y(T)=0, \quad y^{\prime}(t)=x^{\prime}\left(t+\tau_{0}\right) \quad \text { for all } t \in[0, T] .
$$

Thus, from Theorem 225 in [5], (2.5) implies that

$$
|y|_{2} \leq \frac{T}{\pi}\left|y^{\prime}\right|_{2}
$$


In view of the Minkowski inequality, we have

$$
\begin{aligned}
|x|_{2}^{2} & =\int_{\tau_{0}}^{T}|x(t)|^{2} d t+\int_{0}^{\tau_{0}}|x(t)|^{2} d t \\
& =\int_{0}^{T-\tau_{0}}\left|x\left(t+\tau_{0}\right)\right|^{2} d t+\int_{T-\tau_{0}}^{T}\left|x\left(t+\tau_{0}-T\right)\right|^{2} d t \\
& =\left|y(t)+x\left(\tau_{0}\right)\right|_{2}^{2} \leq\left(|y|_{2}+\left|x\left(\tau_{0}\right)\right|_{2}\right)^{2} \leq\left(|y|_{2}+\sqrt{T} D\right)^{2} .
\end{aligned}
$$

Combining (2.6) and (2.7), we obtain

$$
|x|_{2} \leq|y|_{2}+\sqrt{T} D \leq \frac{T}{\pi}\left|y^{\prime}\right|_{2}+\sqrt{T} D=\frac{T}{\pi}\left|x^{\prime}\right|_{2}+\sqrt{T} D .
$$

\section{Main results}

TheOREM 3.1. Let $\int_{0}^{T} f(s) d s=0$. Suppose that one of the following conditions holds:

$$
\begin{array}{ll}
\left(A_{1}\right) \quad a_{2}\left(a_{5}+a_{6}\right)>\frac{1}{2} \tau\left[\left(a_{5}+a_{6}\right)^{2}+a_{6}^{2}\right] \\
\\
a_{2}\left(a_{5}+a_{6}\right)=\frac{1}{2} \tau\left[\left(a_{5}+a_{6}\right)^{2}+a_{6}^{2}\right], \\
\left(A_{2}\right) \quad a_{1}\left(a_{5}+a_{6}\right)+a_{2}\left(a_{3}+a_{4}\right)>\tau\left[\left(a_{3}+a_{4}\right)\left(a_{5}+a_{6}\right)+a_{4} a_{6}\right] .
\end{array}
$$

Then equation (1.1) has at least one T-periodic solution.

Proof. We wish to apply Lemma 2.1. To do this, it suffices to prove that the set of all possible $T$-periodic solutions of equation $(2.1)_{\lambda}$ is bounded.

Let $x(t)$ be such a solution. Since $\int_{0}^{T} f(s) d s=0$, it is easy to see that $F(t)$ is a $T$-periodic function. Let $y(t)=x^{\prime}(t)-\lambda F(t)$. Then we can transform $(2.1)_{\lambda}$ into

$$
\left\{\begin{aligned}
\frac{d x}{d t}= & y(t)+\lambda F(t), \\
\frac{d y}{d t}= & -\lambda\left[\left(a_{1} x(t)+a_{2} x^{n}(t)\right)^{\prime}+\left(a_{3} x(t)+a_{5} x^{n}(t)\right)\right. \\
& \left.+\left(a_{4} x(t-\tau)+a_{6} x^{n}(t-\tau)\right)\right] .
\end{aligned}\right.
$$

Set

$$
\begin{aligned}
V(t)= & {\left[y(t)+\lambda\left(a_{1} x(t)+a_{2} x^{n}(t)\right)-\lambda \int_{t-\tau}^{t}\left(a_{4} x(s)+a_{6} x^{n}(s)\right) d s\right]^{2} } \\
& +2 \lambda \int_{0}^{x}\left(a_{3} u+a_{5} u^{n}\right) d u+2 \lambda \int_{0}^{x}\left(a_{4} u+a_{6} u^{n}\right) d u \\
& +\lambda^{2} \int_{-\tau}^{0} \int_{t+s}^{t}\left(a_{4} x(u)+a_{6} x^{n}(u)\right)^{2} d u d s
\end{aligned}
$$


Since $x(t)$ and $y(t)$ are $T$-periodic, so is $V(t)$. Calculating the derivative of $V$ along the system (3.1), we have

$$
\begin{aligned}
& \left.\frac{d V(t)}{d t}\right|_{(3.1)} \\
& =2\left[y(t)+\lambda\left(a_{1} x(t)+a_{2} x^{n}(t)\right)-\lambda \int_{t-\tau}^{t}\left(a_{4} x(s)+a_{6} x^{n}(s)\right) d s\right] \\
& \quad \times\left[-\lambda\left(a_{3} x(t)+a_{5} x^{n}(t)\right)-\lambda\left(a_{4} x(t)+a_{6} x^{n}(t)\right)\right] \\
& \quad+2 \lambda\left(a_{3} x(t)+a_{5} x^{n}(t)\right) y(t)+2 \lambda^{2}\left(a_{3} x(t)+a_{5} x^{n}(t)\right) F(t) \\
& \quad+2 \lambda\left(a_{4} x(t)+a_{6} x^{n}(t)\right) y(t)+2 \lambda^{2}\left(a_{4} x(t)+a_{6} x^{n}(t)\right) F(t) \\
& \quad+\lambda^{2} \tau\left(a_{4} x(t)+a_{6} x^{n}(t)\right)^{2}-\lambda^{2} \int_{t-\tau}^{t}\left(a_{4} x(u)+a_{6} x^{n}(u)\right)^{2} d u \\
& =-2 \lambda^{2}\left(a_{1} x(t)+a_{2} x^{n}(t)\right)\left[\left(a_{3}+a_{4}\right) x(t)+\left(a_{5}+a_{6}\right) x^{n}(t)\right] \\
& \quad+2 \lambda^{2}\left[\left(a_{3}+a_{4}\right) x(t)+\left(a_{5}+a_{6}\right) x^{n}(t)\right] \int_{t-\tau}^{t}\left(a_{4} x(s)+a_{6} x^{n}(s)\right) d s \\
& \quad+2 \lambda^{2}\left[\left(a_{3}+a_{4}\right) x(t)+\left(a_{5}+a_{6}\right) x^{n}(t)\right] F(t) \\
& +\lambda^{2} \tau\left(a_{4} x(t)+a_{6} x^{n}(t)\right)^{2}-\lambda^{2} \int_{t-\tau}^{t}\left(a_{4} x(u)+a_{6} x^{n}(u)\right)^{2} d u .
\end{aligned}
$$

Integrating (3.3) from 0 to $T$, in view of $V(0)=V(T)$, we see that

$$
\begin{aligned}
& 2 \lambda^{2} \int_{0}^{T}\left(a_{1} x(t)+a_{2} x^{n}(t)\right)\left[\left(a_{3}+a_{4}\right) x(t)+\left(a_{5}+a_{6}\right) x^{n}(t)\right] d t \\
& =2 \lambda^{2} \int_{0}^{T}\left[\left(a_{3}+a_{4}\right) x(t)+\left(a_{5}+a_{6}\right) x^{n}(t)\right] F(t) d t \\
& \quad+2 \lambda^{2} \int_{0}^{T}\left[\left(\left(a_{3}+a_{4}\right) x(t)+\left(a_{5}+a_{6}\right) x^{n}(t)\right) \int_{t-\tau}^{t}\left(a_{4} x(s)+a_{6} x^{n}(s)\right) d s\right] d t \\
& \quad+\lambda^{2} \int_{0}^{T}\left[\tau\left(a_{4} x(t)+a_{6} x^{n}(t)\right)^{2}-\int_{t-\tau}^{t}\left(a_{4} x(u)+a_{6} x^{n}(u)\right)^{2} d u\right] d t \\
& \leq 2 \lambda^{2} \int_{0}^{T}\left[\left(a_{3}+a_{4}\right) x(t)+\left(a_{5}+a_{6}\right) x^{n}(t)\right] F(t) d t
\end{aligned}
$$




$$
\begin{aligned}
& +\lambda^{2} \int_{0}^{T}\left[\int_{t-\tau}^{t}\left(\left(\left(a_{3}+a_{4}\right) x(t)+\left(a_{5}+a_{6}\right) x^{n}(t)\right)^{2}+\left(a_{4} x(s)+a_{6} x^{n}(s)\right)^{2}\right) d s\right] d t \\
& +\lambda^{2} \int_{0}^{T}\left[\tau\left(a_{4} x(t)+a_{6} x^{n}(t)\right)^{2}-\int_{t-\tau}^{t}\left(a_{4} x(u)+a_{6} x^{n}(u)\right)^{2} d u\right] d t
\end{aligned}
$$

which implies that

$$
\begin{aligned}
& \int_{0}^{T}\left(a_{1} x(t)+a_{2} x^{n}(t)\right)\left[\left(a_{3}+a_{4}\right) x(t)+\left(a_{5}+a_{6}\right) x^{n}(t)\right] d t \\
& \leq|F|_{\infty} \int_{0}^{T}\left|\left(a_{3}+a_{4}\right) x(t)+\left(a_{5}+a_{6}\right) x^{n}(t)\right| d t \\
& \quad+\frac{1}{2} \tau \int_{0}^{T}\left[\left(\left(a_{3}+a_{4}\right) x(t)+\left(a_{5}+a_{6}\right) x^{n}(t)\right)^{2}+\left(a_{4} x(t)+a_{6} x^{n}(t)\right)^{2}\right] d t .
\end{aligned}
$$

Using $\left(A_{1}\right)$ (or $\left.\left(A_{2}\right)\right)$, we find that there exist positive constants $D_{1}$ and $\varepsilon$ such that

$$
\begin{aligned}
\left.\left(a_{1} x+a_{2} x^{n}\right)\left[\left(a_{3}+a_{4}\right) x+\left(a_{5}+a_{6}\right) x^{n}\right)\right] & \\
= & \left.\mid\left(a_{1} x+a_{2} x^{n}\right)\left[\left(a_{3}+a_{4}\right) x+\left(a_{5}+a_{6}\right) x^{n}\right)\right] \mid \\
> & \left|\left(a_{3}+a_{4}\right) x+\left(a_{5}+a_{6}\right) x^{n}\right|\left(|F|_{\infty}+\varepsilon\right)+\frac{1}{2} \tau\left[\left(\left(a_{3}+a_{4}\right) x\right.\right. \\
& \left.\left.\quad+\left(a_{5}+a_{6}\right) x^{n}\right)^{2}+\left(a_{4} x+a_{6} x^{n}\right)^{2}\right] \quad \text { for all }|x| \geq D_{1} .
\end{aligned}
$$

Thus, there exists a positive constant $D_{2}$ such that

$$
\begin{aligned}
& \left.\left(a_{1} x+a_{2} x^{n}\right)\left[\left(a_{3}+a_{4}\right) x+\left(a_{5}+a_{6}\right) x^{n}\right)\right] \\
& \geq \mid \\
& \quad\left|\left(a_{3}+a_{4}\right) x+\left(a_{5}+a_{6}\right) x^{n}\right|\left(|F|_{\infty}+\varepsilon\right) \\
& \quad+\frac{1}{2} \tau\left[\left(\left(a_{3}+a_{4}\right) x+\left(a_{5}+a_{6}\right) x^{n}\right)^{2}+\left(a_{4} x+a_{6} x^{n}\right)^{2}\right]-D_{2}
\end{aligned}
$$

for all $x \in \mathbb{R}$. Integrating (3.6) from 0 to $T$, together with (3.4), we obtain

$$
\int_{0}^{T}\left|\left(a_{3}+a_{4}\right) x(t)+\left(a_{5}+a_{6}\right) x^{n}(t)\right| d t \leq \frac{D_{2} T}{\varepsilon}=: D_{3} .
$$

We claim that there must exist a constant $\xi \in[0, T]$ such that

$$
|x(\xi)|<D_{1} .
$$

Assume, by way of contradiction, that (3.8) does not hold. Then

$$
|x(t)| \geq D_{1} \quad \text { for all } t \in \mathbb{R} .
$$

From (3.3), (3.5) and (3.9), we have 
(3.10)

$$
\begin{aligned}
&\left.\frac{d V(t)}{d t}\right|_{(3.1)} \\
& \leq-2 \lambda^{2}\left(a_{1} x(t)+a_{2} x^{n}(t)\right)\left[\left(a_{3} x(t)+a_{5} x^{n}(t)\right)+\left(a_{4} x(t)+a_{6} x^{n}(t)\right)\right] \\
&+\lambda^{2} \tau\left[\left(\left(a_{3}+a_{4}\right) x(t)+\left(a_{5}+a_{6}\right) x^{n}(t)\right)^{2}+\left(a_{4} x(t)+a_{6} x^{n}(t)\right)^{2}\right] \\
&+2 \lambda^{2}\left[\left(a_{3}+a_{4}\right) x(t)+\left(a_{5}+a_{6}\right) x^{n}(t)\right] F(t) \\
&<0 \quad \text { for all } t \in[0, T]
\end{aligned}
$$

which contradicts the fact that $V(0)=V(T)$. This contradiction implies that (3.8) holds true. Hence, using the Schwarz inequality and the relation

$$
|x(t)|=\left|x(\xi)+\int_{\xi}^{t} x^{\prime}(s) d s\right| \leq D_{1}+\int_{0}^{T}\left|x^{\prime}(s)\right| d s, \quad t \in[0, T],
$$

we have

$$
|x|_{\infty}=\max _{t \in[0, T]}|x(t)| \leq D_{1}+\sqrt{T}\left|x^{\prime}\right|_{2} .
$$

Now, multiplying equation $(2.1)_{\lambda}$ by $-x(t)$ and integrating from 0 to $T$, taking into account that $a_{1}, \ldots, a_{6}$ are nonnegative constants and $n \geq 3$ is odd, together with (3.7) and (3.10), we obtain

$$
\begin{aligned}
& \int_{0}^{T}\left|x^{\prime}(t)\right|^{2} d t \\
= & \lambda \int_{0}^{T}\left[a_{3} x(t)+a_{4} x(t-\tau)+a_{5} x^{n}(t)+a_{6} x^{n}(t-\tau)-f(t)\right] x(t) d t \\
\leq & |x|_{\infty} \int_{0}^{T}\left[a_{3}|x(t)|+a_{4}|x(t-\tau)|+a_{5}\left|x^{n}(t)\right|+a_{6}\left|x^{n}(t-\tau)\right|+|f(t)|\right] d t \\
= & |x|_{\infty} \int_{0}^{T}\left[\left(a_{3}+a_{4}\right)|x(t)|+\left(a_{5}+a_{6}\right)\left|x^{n}(t)\right|+|f(t)|\right] d t \\
= & |x|_{\infty} \int_{0}^{T}\left|\left(a_{3}+a_{4}\right) x(t)+\left(a_{5}+a_{6}\right) x^{n}(t)\right| d t+|x|_{\infty}|f(t)|_{1} \\
< & \left(D_{3}+|f(t)|_{1}\right)|x|_{\infty} \leq\left(D_{3}+|f(t)|_{1}\right)\left(D_{1}+\sqrt{T}\left|x^{\prime}\right|_{2}\right) .
\end{aligned}
$$

Hence, there exists a positive constant $D_{4}$ such that

$$
\left|x^{\prime}\right|_{2}<D_{4} \text { and }|x|_{\infty}<D_{4},
$$

which, together with equation $(2.1)_{\lambda}$, implies that 


$$
\begin{aligned}
\left|x^{\prime \prime}(t)\right| \leq & a_{1}\left|x^{\prime}(t)\right|+a_{2} n\left|x^{n-1}(t)\right|\left|x^{\prime}(t)\right|+a_{3}|x(t)|+a_{4}|x(t-\tau)| \\
& +a_{5}\left|x^{n}(t)\right|+a_{6}\left|x^{n}(t-\tau)\right|+|f(t)| \\
\leq & a_{1}\left|x^{\prime}(t)\right|+a_{2} n D_{4}^{n-1}\left|x^{\prime}(t)\right|+\left(a_{3}+a_{4}\right) D_{4} \\
& +\left(a_{5}+a_{6}\right) D_{4}^{n}+|f|_{\infty} .
\end{aligned}
$$

Thus,

$$
\begin{aligned}
\int_{0}^{T}\left|x^{\prime \prime}(t)\right| d t \leq & \left(a_{1}+a_{2} n D_{4}^{n-1}\right) \sqrt{T}\left|x^{\prime}(t)\right|_{2} \\
& +\left[\left(a_{3}+a_{4}\right) D_{4}+\left(a_{5}+a_{6}\right) D_{4}^{n}+|f|_{\infty}\right] T \\
\leq & \left(a_{1}+a_{2} n D_{4}^{n-1}\right) \sqrt{T} D_{4} \\
& +\left[\left(a_{3}+a_{4}\right) D_{4}+\left(a_{5}+a_{6}\right) D_{4}^{n}+|f|_{\infty}\right] T .
\end{aligned}
$$

Since $x(0)=x(T)$, there exists a constant $\zeta \in[0, T]$ such that

$$
x^{\prime}(\zeta)=0
$$

and

$$
\left|x^{\prime}(t)\right|=\left|x^{\prime}(\zeta)+\int_{\zeta}^{t} x^{\prime \prime}(s) d s\right| \leq \int_{0}^{T}\left|x^{\prime \prime}(t)\right| d t
$$

Combining this and (3.13), we see that there exists a constant $M_{1}$ such that

$$
\|x\|_{X} \leq|x|_{\infty}+\left|x^{\prime}\right|_{\infty}<M_{1}
$$

If $x \in \Omega_{1}=\{x \in \operatorname{Ker} L \cap X \mid N x \in \operatorname{Im} L\}$, then there exists a constant $M_{2}$ such that

$$
x(t) \equiv M_{2}, \quad \int_{0}^{T}\left[a_{3} M_{2}+a_{4} M_{2}+a_{5} M_{2}^{n}+a_{6} M_{2}^{n}-f(t)\right] d t=0,
$$

which, together with $\left(A_{1}\right)$ (or $\left.\left(A_{2}\right)\right)$, implies that there exists a positive constant $D_{5}$ such that

$$
|x(t)| \equiv\left|M_{2}\right|<D_{5} \quad \text { for all } x(t) \in \Omega_{1} .
$$

Since $\left(A_{1}\right)$ (or $\left.\left(A_{2}\right)\right)$ holds, there exists a constant $\bar{D}>D_{5}$ such that

$$
x\left[a_{3} x+a_{4} x+a_{5} x^{n}+a_{6} x^{n}-f(t)\right]>0 \quad \text { for all }|x| \geq \bar{D} .
$$

Let $M=M_{1}+\bar{D}$. Set

$$
\Omega=\left\{\left.x \in X|| x\right|_{\infty}<M,\left|x^{\prime}\right|_{\infty}<M\right\} .
$$

It is easy to see from (1.3) and (1.4) that $N$ is $L$-compact on $\bar{\Omega}$. It follows from (3.14), (3.15) and the fact that $M>\max \left\{M_{1}, D_{5}\right\}$ that conditions (1) and (2) of Lemma 2.1 are satisfied. 
Furthermore, we define continuous functions $H(x, \mu)$ by setting

$$
\begin{aligned}
H(x, \mu)= & -(1-\mu) x \\
& -\mu \cdot \frac{1}{T} \int_{0}^{T}\left[a_{3} x+a_{4} x+a_{5} x^{n}+a_{6} x^{n}-f(t)\right] d t, \quad \mu \in[0,1] .
\end{aligned}
$$

In view of (3.16), we obtain

$$
x H(x, \mu) \neq 0 \quad \text { for all } x \in \partial \Omega \cap \operatorname{Ker} L, \mu \in[0,1] .
$$

Hence, using the homotopy invariance theorem, we have

$$
\begin{aligned}
& \operatorname{deg}\left\{\left.Q N\right|_{N(L)}, \Omega \cap \operatorname{Ker} L, 0\right\} \\
& =\operatorname{deg}\left\{-\frac{1}{T} \int_{0}^{T}\left[a_{3} x+a_{4} x+a_{5} x^{n}+a_{6} x^{n}-f(t)\right] d t, \Omega \cap \operatorname{Ker} L, 0\right\} \\
& =\operatorname{deg}\{-x, \Omega \cap \operatorname{Ker} L, 0\} \neq 0 .
\end{aligned}
$$

In view of the above discussion, we conclude from Lemma 2.1 that Theorem 3.1 holds.

THEOREM 3.2. Suppose that one of the following conditions holds.

$\left(A_{4}\right) \quad a_{1}>0, \quad a_{3}+a_{4}+a_{5}+a_{6}>0, \quad \tau=k T$ and $k$ is an integer.

Then equation (1.1) has at least one T-periodic solution.

Proof. Let $x(t)$ be a $T$-periodic solution of equation $(2.1)_{\lambda}$. Integrating $(2.1)_{\lambda}$ from 0 to $T$, we see that

$$
\begin{aligned}
& \int_{0}^{T}\left[\left(a_{3}+a_{4}\right) x(t)+\left(a_{5}+a_{6}\right) x^{n}(t)\right] d t \\
& =\int_{0}^{T}\left[a_{3} x(t)+a_{4} x(t-\tau)+a_{5} x^{n}(t)+a_{6} x^{n}(t-\tau)\right] d t=\int_{0}^{T} f(t) d t .
\end{aligned}
$$

Thus, there exists a constant $\eta \in[0, T]$ such that

$$
\left(a_{3}+a_{4}\right)|x(\eta)|+\left(a_{5}+a_{6}\right)\left|x^{n}(\eta)\right| \leq|f|_{\infty} .
$$

From $\left(A_{3}\right)$ (or $\left(A_{4}\right)$ ), it follows that there exists a positive constant $N_{1}$ such that

$$
|x(\eta)|<N_{1} .
$$

Multiplying $(2.1)_{\lambda}$ by $x^{\prime}(t)$ and integrating from 0 to $T$, we have

$$
\begin{aligned}
& \int_{0}^{T} a_{1}\left|x^{\prime}(t)\right|^{2} d t \leq \int_{0}^{T}\left(a_{1}+a_{2} n x^{n-1}(t)\right)\left|x^{\prime}(t)\right|^{2} d t \\
& =-\int_{0}^{T}\left[a_{3} x(t)+a_{4} x(t-\tau)+a_{5} x^{n}(t)+a_{6} x^{n}(t-\tau)-f(t)\right] x^{\prime}(t) d t .
\end{aligned}
$$


If $\left(A_{3}\right)$ holds, then, by $(2.4),(3.18)$ and the Schwarz inequality, we have

$$
\begin{aligned}
a_{1}\left|x^{\prime}(t)\right|_{2}^{2} & \leq \int_{0}^{T}\left[a_{4}|x(t-\tau)|+|f(t)|\right]\left|x^{\prime}(t)\right| d t \leq a_{4}|x|_{2}\left|x^{\prime}\right|_{2}+|f|_{2}\left|x^{\prime}\right|_{2} \\
& \leq \frac{T}{\pi} a_{4}\left|x^{\prime}\right|_{2}^{2}+\left(a_{4} \sqrt{T} N_{1}+|f|_{2}\right)\left|x^{\prime}\right|_{2} .
\end{aligned}
$$

In view of $\left(A_{3}\right)$, there exists a positive constant $N_{2}$ such that

$$
\left|x^{\prime}\right|_{2}<N_{2} \text {. }
$$

If $\left(A_{4}\right)$ holds, (3.18) implies that

$$
a_{1}\left|x^{\prime}(t)\right|_{2}^{2} \leq|f|_{2}\left|x^{\prime}\right|_{2}
$$

Therefore, (3.19) also holds.

Now the proof proceeds in the same way as in Theorem 3.1 and is therefore omitted.

THEOREM 3.3. Suppose that the following condition is satisfied:

$$
\left(a_{3}+a_{4}\right) \frac{T^{2}}{2 \pi^{2}}<1, \quad a_{2}=a_{5}=a_{6}=0, \quad a_{3}+a_{4}>0 .
$$

Then equation (1.1) has at least one T-periodic solution.

Proof. Let $x(t)$ be a $T$-periodic solution of $(2.1)_{\lambda}$. In view of $\left(A_{5}\right)$, it is easy to prove that (3.17) holds. Multiplying $(2.1)_{\lambda}$ by $x^{\prime \prime}(t)$ and integrating from 0 to $T$, by $(2.2),(2.4),(3.17),\left(A_{5}\right)$ and the Schwarz inequality, we have

$$
\begin{aligned}
\left|x^{\prime \prime}\right|_{2}^{2} & =\int_{0}^{T}\left|x^{\prime \prime}(t)\right|^{2} d t \\
& =-\lambda \int_{0}^{T}\left[a_{1} x^{\prime}(t)+a_{3} x(t)+a_{4} x(t-\tau)+f(t)\right] x^{\prime \prime}(t) d t \\
& \leq\left(a_{3}+a_{4}\right)|x|_{2}\left|x^{\prime \prime}\right|_{2}+|f|_{2}\left|x^{\prime \prime}\right|_{2} \\
& \leq\left(a_{3}+a_{4}\right) \frac{T^{2}}{2 \pi^{2}}\left|x^{\prime \prime}\right|_{2}^{2}+\left[\left(a_{3}+a_{4}\right) \sqrt{T} N_{1}+|f|_{2}\right]\left|x^{\prime \prime}\right|_{2},
\end{aligned}
$$

which, together with (3.17) and $\left(A_{5}\right)$, implies that there exist positive constants $D_{1}$ and $D_{2}$ such that

$$
\begin{gathered}
\left|x^{\prime \prime}\right|_{2}<D_{1}, \\
\left|x^{\prime}\right|_{2}<D_{2}, \quad|x|_{\infty}<D_{2} .
\end{gathered}
$$

Now the rest of the proof is similar to the proof of Theorem 3.1 and is therefore omitted. 


\section{Examples and remarks}

EXAMPLE 4.1. The Liénard equation

$$
\begin{aligned}
x^{\prime \prime}+20 x^{\prime}(t)+100\left(x^{5}(t)\right)^{\prime}+10 x(t) & +20 x(t-28) \\
& +4 x^{5}(t)+2 x^{5}(t-28)=\cos t
\end{aligned}
$$

has at least one $2 \pi$-periodic solution.

Proof. By (4.1), we have $a_{1}=20, a_{2}=100, a_{3}=10, a_{4}=20, a_{5}=4$, $a_{6}=2$, the delay $\tau=28, n=5$, and $f=\cos t$ is a continuous periodic function with period $2 \pi$. It is straightforward to check that all conditions of Theorem 3.1 are satisfied. Therefore equation (4.1) has at least one $2 \pi$-periodic solution.

REMARK 4.1. Equation (4.1) is a very simple second order delay differential equation. However, it is easy to check that no results in $[2,4,6-15]$ and the references therein are applicable to (4.1). On the other hand, to the best of our knowledge, the existence of periodic solutions of (1.1) with $a_{i} \geq 0$ $(i=1,2, \ldots, 6)$ has not been studied in previous works. This implies that the results of this paper are essentially new.

\section{References}

[1] T. A. Burton, Stability and Periodic Solutions of Ordinary and Functional-Differential Equations, Academic Press, Orlando, FL, 1985.

[2] C. H. Feng, On the existence and uniqueness of almost periodic solutions for some delay differential equations appearing in a power system, Acta Math. Sinica 46 (2003), 931-936 (in Chinese).

[3] R. E. Gaines and J. Mawhin, Coincidence Degree, and Nonlinear Differential Equations, Lecture Notes in Math. 568, Springer, 1977.

[4] R. B. Grafton, Periodic solutions of certain Liénard equations with delay, J. Differential Equations 11 (1972), 519-527.

[5] G. H. Hardy, J. E. Littlewood and G. Pólya, Inequalities, Cambridge Univ. Press, London, 1964.

[6] X. K. Huang and Z. G. Xiang, On existence of $2 \pi$-periodic solutions for delay Duffing equation $x^{\prime \prime}+g(t, x(t-\tau(t)))=p(t)$, Chinese Sci. Bull. 39 (1994), 201-203 (in Chinese).

[7] R. Iannacci and M. N. Nkashama, On periodic solutions of forced second order differential equations with a deviating argument, in: Lecture Notes in Math. 1151, Springer, 1984, 224-232.

[8] G. J. Ji, Z. X. Wang, and D. W. Lai, Existence of periodic solutions to overvoltage models in electric power systems, Acta Math. Sci. 16 (1996), 99-104 (in Chinese).

[9] D. W. Lai and Z. X. Wang, A delay differential equation appearing in the study of overvoltage, Report to the Italian Symposium 12 (1984), 88-156.

[10] Y. K. Li, Periodic solutions of the Liénard equation with deviating arguments, J. Math. Res. Exposition 18 (1998), 565-570 (in Chinese).

[11] B. Liu and J. S. Yu, On the existence of harmonic solution for the $n$-dimensional Liénard equations with delay, Acta Math. Sci. Ser. A 22 (2002), 323-331 (in Chinese). 
[12] S. P. Lu and W. G. Ge, Periodic solutions of a second order differential equation with deviating arguments, Acta Math. Sinica 45 (2002), 811-818 (in Chinese).

[13] - - - On the existence of periodic solutions for a kind of second order $n$-dimensional neutral differential systems, ibid. 46 (2003), 601-610 (in Chinese).

[14] J. Mawhin, An extension a theorem of A .C. Lazer on forced nonlinear oscillations, J. Math. Anal. Appl. 40 (1972), 20-29.

[15] —, Periodic solutions of some vector retarded functional differential equations, ibid. 45 (1974), 588-603.

Department of Mathematics

Hunan University of Arts and Science

Changde, Hunan 415000, P.R. China

E-mail: liubw007@yahoo.com.cn
College of Mathematics and Econometrics

Hunan University Changsha 410082, P.R. China

Reçu par la Rédaction le 18.4.2005

Révisé le 29.9.2005 